\title{
Recommendation of RILEM TC 190-SBJ: service-life prediction of sealed building and construction joints
}

\section{Durability test method: determination of changes in adhesion, cohesion and appearance of elastic weatherproofing sealants after exposure of statically cured specimens to artificial weathering and mechanical cycling*}

\author{
RILEM Technical Committee (Andreas T. Wolf)**
}

Published online: 23 September 2008

(C) RILEM 2008

\section{Introduction}

Weatherproofing joint seals in building façades or other construction applications are exposed to thermally or psychrometrically induced cyclic movements. This joint movement imposes cyclic mechanical strain on the seal, which, depending on the

\footnotetext{
*The text presented hereafter is a draft for general consideration.

Comments should be sent within 6 months of publication to the TC chairman, Dr. Andreas T. Wolf, Dow Corning GmbH, Rheingaustrasse 34, 65201 Wiesbaden, Germany, Fax: +49 (611) 237.627,

E-mail: andreas.wolf@dowcorning.com.
}

**This recommendation was developed by a work group within RILEM TC190-SBJ under the leadership of Mr. Noriyoshi Enomoto, Japan and Mr. Andreas T. Wolf, Germany, in close cooperation with ISO TC59/SC8.

TC-Membership:

Chairman: A.T. Wolf, Germany.

Secretary: N.N.

Members: J. Beasley, United Kingdom; L.D. Carbary, U.S.A.; P.D. Gorman, U.S.A.; A.R. Hutchinson, United Kingdom; J.M. Klosowski, USA; M.A. Lacasse, Canada;

K. Tanaka, Japan.

RILEM Technical Committee 190-SBJ

(Andreas T. Wolf) ( $\square$ )

Dow Corning GmbH, Rheingaustrasse 34,

65201 Wiesbaden, Germany

e-mail: andreas.wolf@dowcorning.com exposure conditions and the construction design, can vary substantially in rate and amplitude. During their entire service life, joint seals are exposed to cyclic mechanical strain and environmental degradation factors. Cyclic joint movement, sunlight, temperature variations (heat, cold) and moisture in the form of humidity, condensation or rain are considered to be the primary environmental and service degradation factors leading to sealed joint failure.

This technical recommendation provides a framework for assessing the effects of cyclic movement and weathering on statically cured test specimens in laboratory-based procedures. While default values for the test parameters are provided in the test method, the experimenter is allowed to adapt test conditions to better reproduce local climatic or service conditions, so long as any deviations from the default are reported.

\section{Scope}

This RILEM recommendation specifies laboratory exposure procedures for determining the effects of cyclic movement and artificial weathering on cured, elastic weatherproofing joint sealants (one- or multicomponent).

\section{Safety concerns}

This standard does not purport to address safety concerns, if any, associated with its use. It is the 
responsibility of the user of this recommendation to establish appropriate safety and health practices and determine the applicability of regulatory limitations prior to use.

\section{Related standards}

Laboratory-based accelerated weathering methods described in this recommendation are technically related to those published in ASTM C1519, ASTM G151, ASTM G152, ASTM G154, ASTM G155, ISO 4892-1, ISO 4892-2, ISO 4892-3, and ISO 11431.

\section{Normative references}

The following standards contain provisions, which, through reference in this text, constitute provisions of this RILEM Technical Recommendation (RTR). At the time of publication, the editions indicated were valid.

\subsection{ASTM standards}

ASTM C1519 (2004) Standard Practice for Evaluating Durability of Building Construction Sealants by Laboratory Accelerated Weathering Procedures.

ASTM G151 (2000) Standard Practice for Exposing Non-metallic Materials in Accelerated Test Devices that Use Laboratory Light Sources.

ASTM G152 (2006) Standard Practice for Operating Open Flame Carbon Arc Light Apparatus for Exposure of Non-metallic Materials.

ASTM G154 (2006) Standard Practice for Operating Fluorescent Light Apparatus for UV Exposure of Non-metallic Materials.

ASTM G155 (2005) Standard Practice for Operating Xenon-Arc Light Apparatus for Exposure of Nonmetallic Materials.

\subsection{CIE standard}

CIE Publication No. 85 (1989) Recommendations for the Integrated Irradiance and the Spectral Distribution of Simulated Radiation for Testing Purposes; Solar Spectral Irradiance, ISBN 3900734224.

\subsection{ISO standards}

ISO 4892-1 (1999) Plastics-Methods of Exposure to Laboratory Light Sources-Part 1: General Guidance.

ISO 4892-2 (2006) Plastics-Methods of Exposure to Laboratory Light Sources-Part 2: Xenon Lamps.

ISO 4892-3 (2006) Plastics-Methods of Exposure to Laboratory Light Sources-Part 3: Fluorescent UV Lamps.

ISO 4892-4 (2004/Cor 1:2005) Plastics-Methods of Exposure to Laboratory Light Sources-Part 4: Open-flame Carbon-arc Lamps.

ISO 6927 (1981) Building Construction-Jointing Products-Sealants Vocabulary.

ISO 11431 (2002) Building Construction-Jointing Products-Determination of Adhesion/ Cohesion Properties of Sealants after Exposure to Heat, Water and Artificial Light Through Glass. ISO 11600 (2002) Building Construction-Jointing products-Classification and Requirements for Sealants.

ISO 13640 (1999) Building Construction-Jointing Products-Specifications for Test Substrates.

\subsection{Japanese standards}

JIS A 5758-2004 Sealants for Sealing and Glazing in Buildings.

JIS A 1439-2004 Test Methods of Sealants for Sealing and Glazing in Buildings.

\section{Definitions}

For the purpose of this RTR, the definitions provided in ISO 6927 apply.

\section{Summary of test procedure (principle)}

Test specimens are prepared in which the sealant to be tested adheres to two parallel support surfaces (substrates). The specimens are conditioned statically (no movement) in a laboratory controlled climate. The conditioned specimens are then exposed to repetitive cycles of artificial weathering (light, heat and moisture) and cyclic movement under controlled environmental conditions. 
The novel design of the support, which incorporates pivoted hinges, allows simultaneous extension and compression of the sealant in different areas of the test specimen. Simultaneous extension and compression of the test specimen is induced by extending or compressing one end of the test specimen with a suitable device, for instance a fully automated cyclic movement machine, a tensile test machine, or a hand-operated vice, and inserting the separator (see Sect. 9.4) upon completion of the operation in the extended end of the specimen.

Weathering is carried out for 6 weeks (default value) in an artificial weathering machine. Then the specimens are exposed to 6 weeks (default value) of movement cycles. Alternatively, the specimens may be exposed to 6 weeks of movement and artificial weathering carried out simultaneously. The combination of artificial weathering and mechanical movement regimes, carried out either sequentially or simultaneously, constitutes an exposure cycle.

After completion of each exposure cycle, the specimens are extended to the full rated movement capability of the sealant tested and held there as the sealant beads are visually examined for changes in appearance, cohesion and adhesion. The depth of any cohesive or adhesive flaw is determined according to the rules provided in ISO 11600 and the general condition of the sealant is reported. The weathering exposure, the cyclic movement, and the examination for failures constitute a degradation cycle and the degradation cycle is repeated as often as required to achieve a certain degradation.

A schematic representation of the test procedure is shown in Fig. 1a and b.

Default test parameters and, for some procedures, alternative options are defined in this technical recommendation (see Table 1). In cases of dispute, the default method is the reference method. The experimenter may deviate from the default values for the following test parameters (deviations from the default values must be highlighted in the test report):

(a) Support substrate-default: anodised aluminium as specified in ISO 13640;

(b) L-shaped support element dimensions-default: $120 \mathrm{~mm} \times 20 \mathrm{~mm} \times 15 \mathrm{~mm} \times 2.0 \mathrm{~mm}$ (length $\times$ width $\times$ height $\times$ thickness);

(c) Sealed joint dimensions-default: $100 \mathrm{~mm} \times$ $20 \mathrm{~mm} \times 15 \mathrm{~mm}$ (length $\times$ width $\times$ depth); (d) Conditioning method (A or B)—default: A;

(e) Artificial light source (xenon-arc, fluorescent UVA-340 lamp, open-flame carbon arc) default: xenon-arc;

(f) Weathering procedure (default period: 6 weeks): duration of artificial weathering, type of water exposure (spraying or immersion), the temperature of light exposure, the temperature of water exposure, the timing of light and moisture/water cycle-default values are specified for xenon-arc/ water-spray, xenon-arc/water immersion, fluorescent UVA-340/water-spray weathering and open-flame carbon arc/water spray weathering;

(g) Mechanical cycling (default period: 6 weeks): amplitude and duration (number of cycles) default values are specified in the test procedure.

In the future, it is hoped that the test parameters can be linked with specific climatic zones and actual exposure conditions on site.

\section{Significance and use}

The use of this method is intended to induce property changes in sealants associated with typical end use conditions. The repeated exposure of sealant specimens to cycles of artificial weathering and cyclic movement is meant to simulate the effect of a natural weathering environment on installed weatherproofing sealants exposed to outdoor weather and joint movement. Exposures are not intended to simulate the deterioration caused by localised environmental conditions, such as atmospheric pollution, biological attack or salt-water exposure. Laboratory procedures provided in this recommendation are not suitable for evaluating the behaviour of sealants under dynamic cure conditions (movement during cure).

Since the natural environment varies with respect to time, geography and topography, it may be expected that the effects of natural weathering will vary accordingly. Therefore, the correlation of the test data obtained using this experimental procedure with the behaviour of a sealant subjected to actual weathering and service conditions (geographic locations, sealant orientation, et cetera) on a given building is unknown. The use of this method as a predictor of the service life of a sealed joint for a given climate and location and on a given building has not been demonstrated. 
Fig. 1 Schematic flowchart of test procedure shown for (a) sequential weathering and mechanical cycling and (b)

simultaneous weathering and mechanical cycling
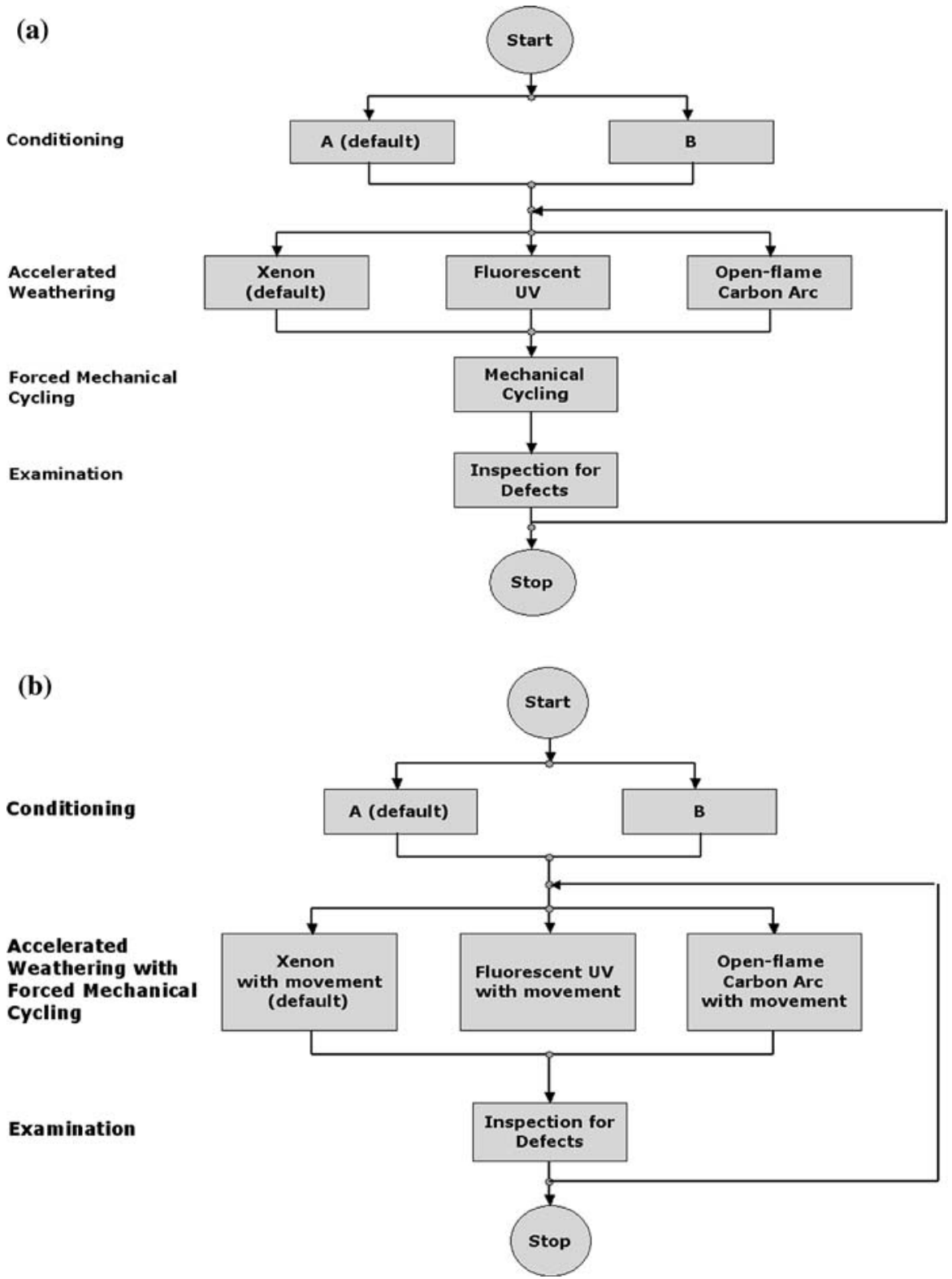

The results obtained with this recommended procedure will vary depending on the choice of the experimental test parameters (light source, exposure temperatures, movement amplitudes, et cetera). When conducting laboratory-based exposures, it is important to consider how well the artificial test conditions reproduce property changes and failure modes associated with end-use environments for the sealants to be tested. The applicability of test data therefore will be at the discretion of the users of this method and depends on their interpretation of the movement and exposure conditions of a given job site situation.

As a method of test, the procedure, in principle, can be practised with any substrate, but the standard (default) test substrate is anodised aluminium. It should be noted that a job site will have many substrates and all or most of them will be different from the standard test substrate. Thus, results obtained with this method using the standard test substrate will not be predictive of actual field adhesion. 
Table 1 Overview of default and alternative choices of key test parameters (for specification of irradiance levels see Sects. 9 and 12)

\begin{tabular}{|c|c|c|}
\hline Procedure & Default & Alternative option or alternative test parameter \\
\hline Conditioning & A & $\mathrm{B}$ \\
\hline \multirow[t]{3}{*}{$\begin{array}{l}\text { Accelerated } \\
\text { weathering } \\
\text { (6 weeks })\end{array}$} & $\begin{array}{l}\text { Xenon-arc light source with daylight filters and water } \\
\text { spray; } 102 \text { min light at } 65 \pm 3^{\circ} \mathrm{C} \text { black standard } \\
\text { thermometer and } 60 \pm 10 \% \text { relative humidity; } \\
18 \text { min light with water spray; } 504 \text { cycles } \\
\text { (6 weeks) }\end{array}$ & $\begin{array}{l}\text { Fluorescent ultraviolet radiation and water-spray } \\
\text { (FL/UVA-340 lamps); } \\
8 \mathrm{~h} \mathrm{UV} \text { at } 65 \pm 3^{\circ} \mathrm{C} \text { black standard thermometer; } \\
4 \mathrm{~h} \text { UV with water spray; } \\
84 \text { cycles ( } 6 \text { weeks) }\end{array}$ \\
\hline & Or & $\mathrm{Or}$ \\
\hline & $\begin{array}{l}\text { Xenon-arc light source with daylight filters and water } \\
\text { immersion; } 102 \text { min light at } 65 \pm 3^{\circ} \mathrm{C} \text { black } \\
\text { standard thermometer; } 18 \text { min light during water } \\
\text { immersion; } 504 \text { cycles ( } 6 \text { weeks) }\end{array}$ & $\begin{array}{l}\text { Open-flame carbon arc light source with daylight } \\
\text { type filter and water spray; } 102 \text { min light at } \\
65 \pm 3^{\circ} \mathrm{C} \text { black standard thermometer and } \\
50 \pm 5 \% \text { relative humidity; } 18 \text { min light with } \\
\text { water spray; } 504 \text { cycles ( } 6 \text { weeks) }\end{array}$ \\
\hline $\begin{array}{l}\text { Movement parameters } \\
\text { for mechanical } \\
\text { cycling ( } 6 \text { weeks })\end{array}$ & $\begin{array}{l}\text { Movement cycling is carried out sequentially with } \\
\text { accelerated weathering- } 1 \text { cycle/96 h ( } 4 \text { days), } \\
\text { specimens at rest (no movement) for } 72 \mathrm{~h} \text { ( } 3 \text { days) } \\
\text { (total duration of weathering and mechanical } \\
\text { cycling: } 12 \text { weeks) }\end{array}$ & $\begin{array}{l}\text { Movement cycling is carried out simultaneously with } \\
\text { accelerated weathering- } 1 \text { cycle } / 96 \mathrm{~h} \text { ( } 4 \text { days), } \\
\text { specimens at rest (no movement) for } 72 \mathrm{~h} \text { ( } 3 \text { days) } \\
\text { (total duration of weathering and mechanical } \\
\text { cycling: } 6 \text { weeks) }\end{array}$ \\
\hline
\end{tabular}

It is strongly recommended that control materials with known durability should be included with each exposure test. Control materials should be exposed along with the test specimens for the purpose of comparing the performance of test materials to the controls. It is preferable to use two control materials of similar composition and construction to the test specimens, one with relatively good durability and one with relatively poor durability. Unless otherwise specified, at least three replicate specimens of each test and control material are to be used.

\section{Apparatus}

\subsection{Support}

Anodized aluminium support (as shown in Fig. 2) for the preparation of test specimens, consisting of two pivoting, L-shaped support elements of dimensions $120 \mathrm{~mm} \times 20 \mathrm{~mm} \times 15 \mathrm{~mm} \times 2.0 \mathrm{~mm}$ (length $\times$ width $\times$ height $\times$ thickness) riveted onto an anodised aluminium base-plate. Riveting of the support elements on the base-plate shall be such that they can be turned freely with minimal friction on the pivot (fulcrum). For the specification of the anodised aluminium, refer to ISO 13640. If other support materials are to be used, they must be characterised and must be described in the test report. If other support dimensions are used, they must be described in the test report and care must be taken to ensure the same level of irradiance and water exposure at the specimen surface as described in Sects. 9.9 and 12.

\subsection{Spacers}

Spacers for the preparation of the specimens, of dimensions $20 \mathrm{~mm} \times 15 \mathrm{~mm} \times 10 \mathrm{~mm}$, with antiadherent surface (see Fig. 2a-c) shall be used. If the spacers are made of material to which the sealant adheres, their surface must be made anti-adherent, e.g. by a thin wax coating.

\subsection{Anti-adherent substrate (bond breaker)}

Anti-adherent substrate for the preparation of test specimens, e.g. polyethylene (PE) or polytetrafluoroethylene (PTFE) film, preferably coated on one face with a pressure-sensitive adhesive (PSA) for easier installation, shall be used, preferably according to the advice of the sealant manufacturer. The anti-adherent substrate shall not restrict the movement of the L-shaped pivoted support elements.

\subsection{Separators}

Separators, of appropriate dimensions shall be used to hold the test specimens in extension up to the rated movement capability of the sealant. 

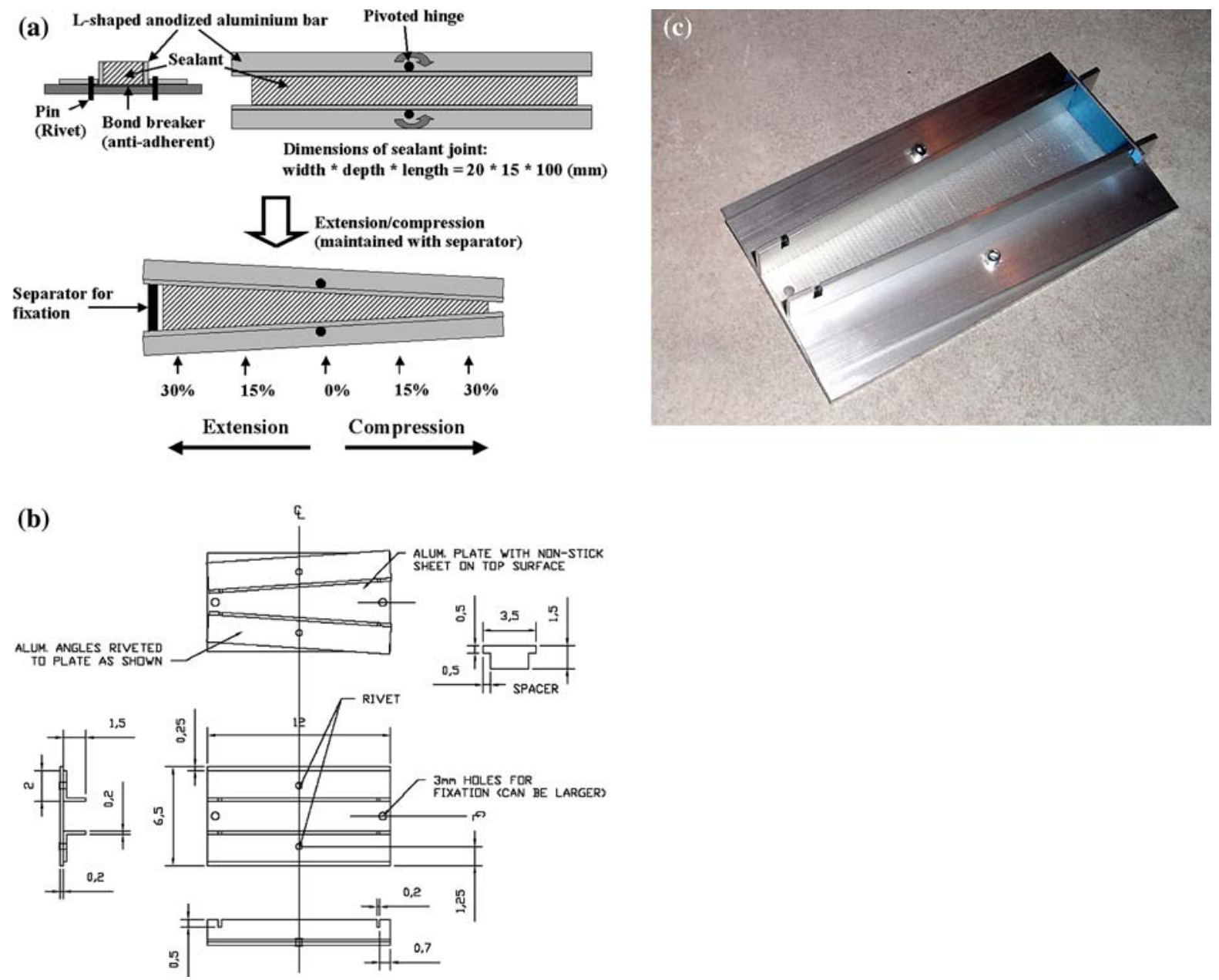

Fig. 2 (a) Schematic drawing of test specimen: sealant in anodised aluminium support used for cyclic mechanical movement of sealant; (b) engineering drawing of support (all

\subsection{Container}

Container filled with demineralised or distilled water shall be used for conditioning according to Method B.

\subsection{Ventilated convection-type oven}

Ventilated convection-type oven, capable of being maintained at $70 \pm 2{ }^{\circ} \mathrm{C}$, shall be used for conditioning according to Method B.

\subsection{Cyclic movement devices or manual cycling}

Automatic cyclic movement device capable of extension and compression at a rate of $5.5 \pm 0.7 \mathrm{~mm} / \mathrm{min}$

measurements in centimetres); (c) photo of support used for cyclic mechanical movement of sealant

shall be used. Alternatively, simultaneous extension and compression of the test specimen may be achieved by extending one end of the test specimen with a suitable extensometer, capable of extension at a rate of $5.5 \pm 0.7 \mathrm{~mm} / \mathrm{min}$, and inserting the separator (see Sect. 9.4) upon completion of the extension. For manual cycling, pliers (vice) are used as a hand-operated device to insert the spacer.

\subsection{Fully automated test chamber with an artificial light source}

Fully automated test chamber with an artificial light source (see Sect. 9.9) shall be used capable of exposing the test specimens to radiation under 
controlled conditions of temperature, relative humidity, and water, complying with the requirements of ISO 4892, Parts 1, 2, 3 and 4 . The radiation is always directed towards the same surface of the sealant specimen. Standard practices for operating such accelerated weathering chambers are described in ISO 4892-1.

In fully automated test equipment, exposure to water for this test method is accomplished by water spraying the specimen surface or immersing the test specimens in water. ${ }^{1,2}$ Contamination of the water is to be avoided. The purity of the water to be used is described in ISO 4892, Part 1. The spray and immersion water is kept at a constant temperature, which shall be below $40^{\circ} \mathrm{C}$.

Suitable equipment and test procedures for cyclic exposures to water are described in ISO 4892, Parts 1, 2, 3 and 4. Water is a key factor contributing to the ageing of sealants, especially in combination with exposure to light. In xenon-arc devices that use water spray for wetting, relative humidity during the light period shall be maintained at $60 \pm 10 \%$ r.h. ${ }^{3}$

In the immersion technique, the test specimens are placed in a chamber that is periodically flooded with

\footnotetext{
${ }^{1}$ For adequate heat transfer to occur during the condensation period in the fluorescent $\mathrm{UV} /$ condensation device a specimen thickness of less than $20 \mathrm{~mm}$ is required (dimensions of the support included). Since the condensation process provided in the fluorescent UV/condensation apparatus is generally not applicable to the type of sealant specimens tested, wetting in this RTR is carried out by water spray on the exposed specimen surface. However, the front surface water spray accessory was not designed for this purpose and requires an unreasonable amount of pure water for the wet period specified. Therefore, in order to comply with the specification, the equipment requires modification to recirculate the water during the exposure period.

${ }^{2}$ Data generated with these two methods of water exposure (spray or immersion) in a round robin test on a set of sealants for revision of ISO 11431 showed acceptable correlation, although contributions to the various degradation mechanisms acting in the specimens (e.g. hydrolysis, thermal shock, leaching of formulation components, et cetera) can differ between these exposures. The degree of correlation between these two methods thus may vary depending on the specific sealant tested.

3 The revision of ISO 4892-2 (xenon arc exposure) proposed by ISO/TC 61/SC 6/WG2 in 2001 specifies relative humidity control at $60 \pm 10 \%$ Generally, automated weathering equipment based on xenon-arc light with water immersion exposure and fluorescent UV lamp type equipment do not allow control of humidity during the light period.
}

either re-circulated or running water. During immersion, the specimens are completely covered by water. The water temperature is measured below the water surface with the black standard thermometer. The immersion system shall be made from corrosion resistant materials that do not contaminate the water employed.

\subsection{Artificial light source}

Light sources for the simulation of the global radiation at the surface of the earth are subject to development. The degree of approximation to the spectral power distribution according to CIE publication no. 85 (Table 4) depends on the type of lamp. Xenon-arc lamps with suitable filters are regarded as adequate and are considered the default for the purpose of this RTR.

Several factors can change the intensity and the spectral power distribution of the artificial light source during service. The experimenter must comply with the manufacturer's recommendations and the requirements of ISO 4892 to maintain constant irradiation conditions.

\subsubsection{Xenon-arc light source (default)}

Xenon-arc light source with daylight filters shall be used for the simulation of terrestrial daylight as defined in the CIE publication no. 85 (1989). The spectral power distribution of the radiation shall comply with the requirements outlined in ISO 4892, Part 2, Method A. Irradiance at the surface of the test specimens between the wavelengths of 300 and $800 \mathrm{~nm}$ shall be set at $550 \mathrm{~W} / \mathrm{m}^{2}$ and maintained at $\pm 75 \mathrm{~W} / \mathrm{m}^{2}$. The equivalent irradiance setting for $300-400 \mathrm{~nm}$ shall be $60 \mathrm{~W} / \mathrm{m}^{2}$ maintained at $\pm 2 \mathrm{~W} / \mathrm{m}^{2}$ and the setting for $340 \mathrm{~nm}$ shall be $0.51 \mathrm{~W} /\left(\mathrm{m}^{2} \mathrm{~nm}\right)$ maintained at $\pm 0.02 \mathrm{~W} /\left(\mathrm{m}^{2} \mathrm{~nm}\right)$. If, exceptionally, other intensities will be used, these shall be stated in the test report. Irradiance below $300 \mathrm{~nm}$ shall not exceed $1 \mathrm{~W} / \mathrm{m}^{2}$. The irradiance shall not vary by more than $\pm 10 \%$ over the whole specimen exposure area.

\subsubsection{Fluorescent ultraviolet source (option)}

Fluorescent UVA-340 lamp(s) shall be used. The radiation of UVA-340 lamp(s) is mainly in the 
ultraviolet region with negligible visible and infrared radiation. The spectral power distribution of the radiation shall comply with the requirements outlined in ISO 4892, Part 3 for a lamp with $343 \mathrm{~nm}$ peak emission. Irradiance below $300 \mathrm{~nm}$ shall not exceed $1 \mathrm{~W} / \mathrm{m}^{2}$. The irradiance shall not vary by more than $\pm 10 \%$ over the whole specimen exposure area.

\subsubsection{Open-flame carbon arc source (option)}

Open-flame carbon arc light sources typically use carbon rods, which contain a mixture of metal salts. An electric current is passed between the carbon rods, which burn and give off ultraviolet, visible, and infrared radiation. Use carbon rods recommended by the device manufacturer. The spectral power distribution of the radiation shall comply with the requirements outlined in ISO 4892, Part 4, openflame carbon arc light source with daylight type filter (Type 1 Filter). ${ }^{4}$

\subsection{Insulated and uninsulated temperature sensors $^{5}$}

Insulated (default) and uninsulated (option) temperature sensors shall comply with the requirements outlined in ISO 4892, Part 1, Sect. 5.1.5. Under given operation conditions black panel (uninsulated) thermometers tend to indicate lower temperatures than the black standard (insulated) thermometers. The temperature difference between the two types ranges between 3 and $12^{\circ} \mathrm{C}$, being smaller at lower irradiance levels. The default thermometer is the black standard thermometer.

\footnotetext{
$\overline{4}$ The chemical composition of the carbon rods can affect the spectral power distribution of open-flame carbon arc light sources.

5 There are inconsistencies between the ISO 4892-1 and ASTM G151 standards in the terminology used for the temperature sensors. In ISO 4892-1, the two types of black temperature sensors are differentiated by referring to the insulated as the "black standard thermometer" and to the uninsulated as the "black panel thermometer". ASTM G151 standard differentiates between the two types by naming them "insulated black panel thermometer" and "uninsulated black panel thermometer". This RTR follows the designation used by ISO 4892-1.
}

The thermometer shall be mounted on the specimen rack so that its surface is in the same relative position and subjected to the same influences as the test specimens. Readings shall only be taken after sufficient time has elapsed for the temperature to become constant.

\section{Preparation of specimens}

Bring the sealant to $23 \pm 2^{\circ} \mathrm{C}$ before preparation of the specimens (this is generally achieved by conditioning the packaged sealant for $24 \mathrm{~h}$ at this temperature). Prepare three specimens. For each specimen, assemble one support (Sect. 9.1) (see Fig. 2), by inserting two spacers (Sect. 9.2) at the ends of the joint. Apply and fix the anti-adherent substrate (Sect. 9.3) to the bottom of the joint (preferably with the help of the PSA).

Follow the instructions of the sealant manufacturer concerning the sealant application, for instance, whether a primer is to be used on the contact surface of the L-shaped support elements.

Fill the hollow volume (dimensions: width $\times$ depth $\times$ length $=20 \mathrm{~mm} \times 15 \mathrm{~mm} \times 100 \mathrm{~mm}$ ) formed by the support and spacers with the sealant, while taking the following precautions:

(a) Avoid the formation of air bubbles;

(b) Press the sealant to the inner surfaces of the pivoted support elements;

(c) Trim the sealant surface so that it is flush with the faces of the support elements and spacers.

\section{Conditioning}

\subsection{General}

Condition the specimens at rest (static conditioning) in accordance with Methods A (default) or B (option), as agreed between the parties concerned.

\subsection{Method A (default)}

Condition the specimens, with the spacers in place, for 28 days at $23 \pm 2{ }^{\circ} \mathrm{C}$ and $50 \pm 5 \%$ relative humidity. After the conditioning, remove the spacers at both sides of the sealant joint. 


\subsection{Method B (option)}

Condition the specimens first according to Method A. Then subject them three times to the following conditioning cycle:

(a) 3 days in the oven (Sect. 9.6) at $70 \pm 2{ }^{\circ} \mathrm{C}$

(b) 1 day in distilled water at $23 \pm 2{ }^{\circ} \mathrm{C}$

(c) 2 days in the oven (Sect. 9.6) at $70 \pm 2{ }^{\circ} \mathrm{C}$

(d) 1 day in distilled water at $23 \pm 2^{\circ} \mathrm{C}$

This cycle may be carried out alternatively in the sequence (c)-(d)-(a)-(b). After the conditioning, remove the spacers at both sides of the sealant joint.

Note: Conditioning $\mathrm{B}$ is a normal conditioning method using the influence of water and heat to accelerate the cure of the sealant. It is not intended to give information on the durability of the sealant.

\section{Test procedures}

\subsection{General}

After conditioning and removal of the spacers, expose the specimens to the artificial weathering cycles and mechanical movement cycles, as agreed by the parties concerned. The choice of the type of accelerated weathering exposure shall be by mutual agreement among the interested parties. Because the different types of exposures may produce different test results, they cannot be used interchangeably without supporting data that demonstrates equivalency of the procedures for the materials tested.

\subsection{Accelerated weathering exposure conditions (default period: 6 weeks)}

During the artificial weathering cycle, expose the test specimens to radiation by the artificial light source such that the specimen test surface faces the lamp. During repeated exposure periods, i.e. when the specimens are exposed to several degradation cycles, direct the radiation always towards the same surface of the sealant. Mount the test specimens so that the plane of the test surface is at a distance from the lamp(s) consistent with the method for operating the apparatus (ISO 4892-2 or 4892-3 or 4892-4). Measure the test temperatures with a black standard thermometer (default) or black panel thermometer (option) (see Sect. 9.10) mounted on the specimen rack so that the face of the temperature sensor is in the same relative position and is subjected to the same influences as the test specimens.

Note 1: The positive and negative deviations from the specified set points for irradiance, temperature and relative humidity are allowable operational fluctuations during equilibrium operation. They do not imply that the user is allowed to program a set point higher or lower than that specified. The maximum operational fluctuation is a critical parameter that assures adequate operation of the equipment. If the operational fluctuations exceed the maximum allowable after the equipment has stabilized, discontinue the test and correct the cause of the problem before continuing.

\subsubsection{Exposure in automatic weathering equipment: xenon-arc type (default)}

The light source shall be one or more xenon-arc lamps with daylight filters installed to simulate terrestrial daylight. The spectral power distribution and the operating practices for the automatic weathering equipment shall be as defined in ISO 4892, Part 2 (and ASTM G155). The irradiance level for the $300-800 \mathrm{~nm}$ spectral region shall be set at $550 \mathrm{~W} / \mathrm{m}^{2}$ and maintained at $\pm 75 \mathrm{~W} / \mathrm{m}^{2}$. The equivalent irradiance setting for $300-400 \mathrm{~nm}$ shall be $60 \mathrm{~W} / \mathrm{m}^{2}$ maintained at $\pm 2 \mathrm{~W} / \mathrm{m}^{2}$ and the setting for $340 \mathrm{~nm}$ shall be $0.51 \mathrm{~W} /\left(\mathrm{m}^{2} \mathrm{~nm}\right)$ maintained at $\pm 0.02 \mathrm{~W} /\left(\mathrm{m}^{2} \mathrm{~nm}\right)$.

The standard conditions of test (default) are repeated cycles of exposure that consist of 6 weeks of exposure in the xenon-arc machine with alternating periods of dry and wet:

(a) A dry period of $102 \mathrm{~min}$, in which the specimens are exposed to radiation and heat. From the start of the dry period the temperature is allowed to rise, until it reaches a steady temperature of $65 \pm 3^{\circ} \mathrm{C}$, as measured on the black standard thermometer (Sect. 9.10). Relative humidity during the dry period is $60 \pm 10 \%$ using the xenon-arc device with water spray. The chamber air temperature in machines that allow for its control shall be $44 \pm 2{ }^{\circ} \mathrm{C}$.

(b) A wet period of $18 \mathrm{~min}$, in which the specimens are exposed to radiation and wetting either by 
water spray on the exposed surface or immersion in water. The water temperature is less than $40^{\circ} \mathrm{C}$.

The cycles of dry and wet exposures are repeated 504 times (default) (6 weeks total duration in the weathering machine).

Filtered xenon arcs provide a good representation of the spectral power distribution as defined in the CIE publication no. 85 and therefore are considered as the reference for the purpose of this recommendation.

\subsubsection{Exposure in automatic weathering equipment: fluorescent UVA-340/water spray type (option)}

The apparatus employed shall conform to the requirements of ISO 4892, Part 3 (and ASTM G154), for a fluorescent UV device with fluorescent UVA-340 lamps having peak emission at $343 \mathrm{~nm}$. The equipment shall be fitted with a suitable spraying unit. It should be noted that for sealants sensitive to long wavelength UV and visible radiation, the absence of this radiation in these lamps may distort stability ranking when compared to exterior environment exposure. In non-irradiance controlled devices, the achievable target value of irradiance depends on the operating temperature. Therefore, use of irradiance-controlled devices is recommended. For the device with UVA-340 lamps operating at $65 \pm 3^{\circ} \mathrm{C}$ black standard thermometer temperature, the target value for irradiance at $340 \mathrm{~nm}$ is $0.75 \mathrm{~W} /\left(\mathrm{m}^{2} \mathrm{~nm}\right)$ maintained at $\pm 0.02 \mathrm{~W} /\left(\mathrm{m}^{2} \mathrm{~nm}\right)$.

The standard conditions of test (default) are repeated cycles of exposure that consist of 6 weeks of exposure in the fluorescent UV/water spray device with alternating periods of dry and wet (temperature and cycle duration specified are defaults; temperatures specified are measured on the black standard thermometer):

(a) Dry Period of Light: $8 \mathrm{~h}$ of UV radiation at $65 \pm 3^{\circ} \mathrm{C}$, followed by

(b) Water Spray Period: $4 \mathrm{~h}$ of UV radiation and water spray on the front surface. The water temperature is less than $40^{\circ} \mathrm{C}$.

The cycles of dry light and light/water spray periods are repeated 84 times (default) (6 weeks total duration in the weathering machine).
12.2.3 Exposure in automatic weathering equipment: open-flame carbon arc (option)

The apparatus employed shall conform to the requirements of ISO 4892, Part 4 (and ASTM G152), for an open-flame carbon-arc light device fitted with a daylight-type (Type 1) filter (see Table 1 in ISO 4892-4). The equipment shall be fitted with a suitable spraying unit. The black standard temperature shall be $65 \pm 3^{\circ} \mathrm{C}$.

The standard conditions of test (default) are repeated cycles of exposure that consist of 6 weeks of exposure in the open-flame carbon-arc light/water spray device with alternating periods of dry and wet (temperature and cycle duration specified are defaults; temperatures specified are measured on the black standard thermometer, air temperature not controlled):

(a) Dry Period of Light: 102 min of light radiation at $65 \pm 3{ }^{\circ} \mathrm{C}$, followed by

(b) Water Spray Period: $18 \mathrm{~min}$ of light radiation and water spray on the front surface. The water temperature is less than $40^{\circ} \mathrm{C}$.

The cycles of dry light and light/water spray periods are repeated 504 times (default) (6 weeks total duration in the weathering machine).

\subsection{Cyclic movement of test specimens}

During or after the accelerated weathering period, expose the specimens to mechanical cycling up to the rated movement capability of the sealant tested (e.g. $\pm 25 \%, \pm 50 \%$ ) either in an automatic cycling device or manually (Sect. 9.7). Simultaneous extension and compression of the test specimen is achieved by extending or compressing one end of the test specimen with a suitable device, for instance a fully automated cyclic movement machine, a tensile test machine, or a hand-operated vice, and inserting the separator (see Sect. 9.4) upon completion of the operation in the extended end of the specimen. The following weekly mechanical exposure cycle is carried out: Mechanical cycling is achieved by extending one end of the test specimen at a rate of $5.5 \pm 0.7 \mathrm{~mm} / \mathrm{min}$, then holding this extension for $48 \mathrm{~h}$. After this period, the test specimen is allowed to relax for $5 \mathrm{~min}$ before the other end of the test specimen is extended at a rate of $5.5 \pm 0.7 \mathrm{~mm} / \mathrm{min}$. 
This extension is again held for $48 \mathrm{~h}$. Then the test specimens are kept in a relaxed (unstressed) state for $72 \mathrm{~h}$ (3 days). The above described weekly mechanical exposure cycle is repeated for a total of 6 weeks. Manual cycling may also be carried out without the extension rate being controlled.

Note that mechanical cycling may also be carried out simultaneously with the accelerated weathering exposure.

\subsection{Examination for defects}

Upon completion of each degradation cycle (weathering and cyclic movement), remove the specimens from the cycling machine and extend them to their rated movement capability using separators (Sect. 9.4) inserted at one end of the specimens. Then examine the specimens for evidence of loss of adhesion or cohesion or any surface changes (cracking, crazing, chalking, et cetera). Whenever adhesion and/or cohesion loss is observed, measure the depth of the cracks using a measuring device capable of reading to $1 \mathrm{~mm}$.

Determine the quantity and width of the cracks for a specific extension/compression value achieved along the length of the specimen ${ }^{6}$ according to Tables 2 and 3, respectively.

Determine the largest observed value for crack density, crack width and crack depth as well as the nature of the failure (adhesive or cohesive) for a specific extension/compression value achieved along the length of the specimen.

Because of the excessive stress experienced by the sealant near the corners of the specimen, during both preparation and testing, loss of adhesion and cohesion is more likely to occur in this region. Determine and report whether the adhesive or cohesive cracks fall within this peripheral region or whether they have propagated further into the bulk of the sealant, in

\footnotetext{
${ }^{6}$ For instance, changes in specimen surface appearance may be reported for $0 \%, 10 \%, 20 \%$, and $30 \%$ tensile compression/ extension movements. Note that the center section of the specimen, while not being exposed to tensile compression/ extension movements, is exposed to a certain, but undefined, amount of shear movement resulting from the displacement of sealant material in the compressed section of the specimen. Therefore, acceleration factors for mechanical movement can not be derived from this test method due to the specimen design.
}

Table 2 Rating for quantity of cracks

\begin{tabular}{ll}
\hline Rating & Quantity of cracks (Q) \\
\hline 0 & None, i.e. no detective cracks \\
1 & Very few, i.e. some just significant cracks \\
2 & Few, i.e. small but significant amount of racks \\
3 & Moderate, i.e. medium amount of cracks \\
4 & Considerable, i.e. serious amount of cracks \\
5 & Dense, i.e. dense pattern of crack \\
\hline
\end{tabular}

Table 3 Rating for width of cracks

\begin{tabular}{ll}
\hline Rating & Width of cracks \\
\hline 0 & Not visible at $10 \times$ magnification \\
1 & Only visible under magnification up to $10 \times$ \\
2 & Just visible with normal (corrected) vision \\
3 & Clearly visible with normal (corrected) vision \\
4 & Large cracks generally up to $1 \mathrm{~mm}$ wide \\
5 & Very large cracks generally more than $1 \mathrm{~mm}$ wide \\
\hline
\end{tabular}

accordance with the requirements defined in ISO 11600.

\subsection{Continuation of degradation cycles}

After examination of the specimens, remove the separators and allow the specimen to relax. Place the specimens in the weathering devices and repeat the procedure described in Sects. 12.1-12.4. The default value for the total number of degradation cycles is four. However, choose the minimum number of degradation cycles such as to induce a substantial (visible) degradation for the least stable material being evaluated.

\section{Test report}

The test report shall include the following information:

(a) The name and address of the test laboratory and date of the test;

(b) The name, colour and type of sealant;

(c) The batch of sealant from which the specimens were produced;

(d) The test substrate;

(e) The primer used, if applicable; 
(f) The method of conditioning used (see Sect. 11);

(g) The experimental weathering parameters used, i.e.

- Type of artificial weathering procedure used (xenon/spray, xenon/immersion, fluorescent UV/spray, open-flame carbon arc/water spray);

- Duration of the artificial weathering exposure cycle;

- Type of light source;

- Irradiance settings;

- Temperature and relative humidity of light exposure;

- Whether humidity has been controlled during the light exposure period;

- Whether chamber air temperature has been controlled during the light exposure period;

- Type of moisture exposure (in spray or immersion) and temperature of water during spray or immersion;

- Timing of light and light/water cycles.

(h) The type of weathering/movement cycle, i.e. sequential weathering and mechanical cycling or simultaneous weathering and mechanical cycling;

(i) Any deviation from the default values specified in this method, e.g.

- Details of the mechanical cycling procedure, if applicable, specifically the amplitude of cycling; whether automatic or manual cycling was employed; whether or not the extension rate was controlled during the manual cycling;

- Nature of the thermometer used (if other than black standard thermometer has been used).

Note: If the experimenter deviates from the default values specified, both the default values as well as the actual conditions used must be reported.

(j) The type of damage (adhesive or cohesive failure as well as changes in surface appearance, such as discoloration), the quantity, width and the maximum depth of cracks (in millimetres), as well as the location of the cracks (bulk or peripheral region), observed after each exposure interval for a specific extension/compression value achieved along the length of the specimen; photographic documentation (minimum $75 \mathrm{~mm} \times 100 \mathrm{~mm}$ print size) of the surface condition of the specimen with a minimum resolution of 800 dpi (31.5 dots per millimetre). Note: This requires a digital camera with a minimum resolution of 8 Megapixel.

(k) The number of degradation cycles;

(l) Any other observations the tester considers important in describing the condition of the specimen.

Acknowledgement The following experts in the field of durability testing of sealants have also substantially contributed to this recommendation: N. Enomoto, Japan; H. Miyauchi, Japan; N. Searle, USA, S. Sugiyama, Japan. Further contributions from members of ISO TC59/SC8 'Building Construction-Sealants' were received and are kindly acknowledged. 